\title{
OPEN Author Correction: Repeated dose multi-drug testing using a microfluidic chip-based coculture of human liver and kidney proximal tubules equivalents
}

\author{
Ni Lin, Xiaobing Zhou, Xingchao Geng, Christopher Drewell, Juliane Hübner, Zuogang Li, \\ Yingli Zhang, Ming Xue, Uwe Marx \& Bo Li
}

Correction to: Scientific Reports, https://doi.org/10.1038/s41598-020-65817-0, published online 01 June 2020

The original version of this Article contained errors. Xiaobing Zhou was incorrectly affiliated with 'Beijing Institute for Drug Control, 25 Science Park Road, Changping District, Beijing, 102206, China'. The correct affiliation is listed below:

Key Laboratory of Beijing for Safety Evaluation of Drugs, National Center for Safety Evaluation of Drugs, National Institutes for Food and Drug Control, A8 Hongda Middle Street, Beijing Economic-Technological Development Area, Beijing, 100176, P. R. China

In addition, the Supplementary Information originally published with this Article contained a typographical error in the spelling of the author Juliane Hübner, which was incorrectly given as Juliane Huebner. The name was correct in the original Article.

Finally, the version of this Article previously published contained lower resolution images for Figures 1, 2, 3, 4, 5, 6, 7, 8 and Supplementary Figure 1.

These errors have now been corrected in the PDF and HTML versions of the Article and in the accompanying Supplementary Information file.

\begin{abstract}
(c) (i) Open Access This article is licensed under a Creative Commons Attribution 4.0 International cc) License, which permits use, sharing, adaptation, distribution and reproduction in any medium or format, as long as you give appropriate credit to the original author(s) and the source, provide a link to the Creative Commons licence, and indicate if changes were made. The images or other third party material in this article are included in the article's Creative Commons licence, unless indicated otherwise in a credit line to the material. If material is not included in the article's Creative Commons licence and your intended use is not permitted by statutory regulation or exceeds the permitted use, you will need to obtain permission directly from the copyright holder. To view a copy of this licence, visit http://creativecommons.org/licenses/by/4.0/.
\end{abstract}

(C) The Author(s) 2020 